\title{
Study of Viscoelastic Behaviour of Cellulose Fluid Carrying Iron Oxide Nanoparticles for Injectable In-Situ Hyperthermia Application
}

\section{Preethi Ramadoss ${ }^{1}$. Smrithy PB ${ }^{2}$. Arivuoli Dakshanamoorthy ${ }^{1}$. Goutam Singh Ningombam ${ }^{4}$. Sabiha Hayath Basha ${ }^{3}$. Nongmaithem Rajmuhon Singh ${ }^{4}$}

\author{
${ }^{1}$ Crystal Growth Centre, Anna University, Chennai, Tamilnadu, India. \\ ${ }^{2}$ University of Kochi, Kochi, Kerala, India. \\ ${ }^{3}$ Centre for Stem Cell Research and Regenerative Medicine, Madras Veterinary College, Chennai, Tamilnadu, India. \\ ${ }^{4}$ Department of Chemistry, Manipur University, Imphal, India.
}

\begin{abstract}
The current study deals with analysis of shear thinning and viscoelastic behaviour of cellulose fluid carrying iron oxide particles for injectable in-situ hyperthermia treatment. The iron oxide nano-particles of size $106 \mathrm{~nm}$ used in the study were synthesized through co-precipitation method using hydrothermal technique and were found to show high coercivity value of 75.83 Oe indicating its good stability. The magnetic nano-particles were suspended in a cellulose fluid for better injectability. This suspension along with the iron-oxide magnetic particles showed good heating efficiency of about $43{ }^{\circ} \mathrm{C}$ in 60 seconds making it ideal for hyperthermia treatment. The specific absorption rate (SAR) and effective specific absorption rate (ESAR) were calculated for the as synthesized nano-particles and for suspension at varying concentrations and it was found that an optimized concentration of $20 \mathrm{mg}$ of the nano-particles dispersed in $5 \mathrm{ml}$ of the polymeric solution was ideal for hyperthermia treatment. The rheological properties studied for the suspension showed that the fluid showed shear-thinning and viscoelastic properties similar to that of human blood making it more suitable for carrying the iron-oxide nano-particles to the tumour site irrespective of the kind of shear stress that it is subjected to. The synthesized particles and the suspension fluid could successfully induce mild heat to the tumour site when delivered through intra-venous route or through intramuscular route thereby aiding radiotherapy and chemotherapy by dilating the blood vessels and thus enabling blood circulation to the poorly oxygenated cancer cells.

(C) 2021 JMSSE $\cdot$ INSCIENCEIN. All rights reserved
\end{abstract}

ARTICLE HISTORY

Received 18-06-2021

Revised 24-07-2021

Accepted 05-08-2021

Published 21-10-2021

\section{KEYWORDS}

Hyperthermia,

Iron oxide nanoparticles

Cellulose suspension

Shear-thinning

Viscoelastic fluid

Lung cancer cells

\section{Introduction}

Intra-tumoral iron oxide nanoparticle thermotherapy is a technique where ferromagnetic particles are directly injected into the tumour tissue with the help of a carrier suspension fluid. An alternating magnetic field (AMF) is applied externally thus leading to a localized heating in the tissue where the magnetic nanoparticles are distributed[1]. The heating mechanism depends on the size, shape and the magnetizing efficiency of the ferromagnetic nano particles. Major disadvantage of this technique of using iron oxide nano particles is that the particles have a greater tendency to aggregate in blood stream which significantly decreases their heating capacity thus leading to a drop in specific absorption rate percentage (SAR) corresponding to loss of energy by the particles to the environment[2]. In order to achieve the desired therapeutic effect of iron oxide nanoparticles, it is necessary to create a localized heating of about $40^{\circ}-45^{\circ} \mathrm{C}$ without affecting the healthy cells surrounding it by achieving high SAR values of the magnetic nano-particles[3]. Hyperthermia by itself may not be an efficient tool for cancer treatment however in combination with chemotherapy and radiotherapy it has shown significant results. Cell death due to hyperthermia occurs by protein denaturation that happens at elevated temperatures[4]. Cancer cells generally survive in hypoxic and acidic conditions[5]. At elevated temperatures there is dilation in the blood vessels connecting to tumour cells which increases perfusion of oxygenated blood in the targeted tissues that helps the tissues become more sensitive to radiotherapy treatment[6]. $0_{2}$ has good electron affinity that participates in the chemical reaction by absorbing energy from the externally applied radiation that leads to DNA damage of the cancer cells[7]. Similarly hyperthermia can induce chemosensitivity in tumour cells by increasing the blood flow through enhanced vascular permeability thus delivering the chemotherapeutic drugs in-vivo[8]. There has been number of clinical trials on hyperthermia treatment in combination with chemotherapy or radiotherapy or both[9]. Jordan et, al.[5] have proved that direct injection of magnetic nanoparticles into the tumour tissues induced better heating efficiency when compared to ultrasound therapy and radiofrequency heating. Besides, hyperthermia also stimulates the migration of immune effector cells and proinflammatory cytokine cells to the malignant tissue site due to higher temperature generated at the site[10].The commonly used particles for magnetic hyperthermiaare ferrite nanoparticles such as magnetite $\left(\mathrm{Fe}_{3} \mathrm{O}_{4}\right)$ or maghemite $\left({ }^{\gamma}-\mathrm{Fe}_{2} \mathrm{O}_{3}\right) . \mathrm{Fe}_{3} \mathrm{O}_{4}$ and ${ }^{\gamma}-\mathrm{Fe}_{2} \mathrm{O}_{3}$ which are referred to asMNPs. When these particles are exposed to alternating magnetic field (AMF) heating occurs via hysteresis loss[11]. In larger magnetic particles where multiple magnetic domains are present, their orientation aligns with the external magnetic field which results in energy difference that gets released in the form of heat, this is called hysteresis loss. Mode of administration of MNPs can be varied according to the type of cancer. Oral administration cannot be carried out for MNPs due to the fact that it will 
get fecally excreted because of its large size. Intra-tumoral has been found effective for localized malignant or benign tumours because MNPs get accumulated on the tumour site and stay there for a longer period of time enabling the hyperthermia treatment on the site repeatedly. In one such case, intra-tumoral injection of MNPs was administered on a patient with prostate cancer and an efficient heating was noticed for the same. The MNPs were also clearly visible via CT scan in the tumoral site for up to 6 weeks in the patient [12]. Intra-peritoneal administration of MNPs has proven efficient with tumours that spread to the peritoneal organs such as ovaries, pancreas, etc. Gao., et. al[13]., have studied that there was significant uptake of MNPs by both the primary and metastasis cancer cells when administered intra-peritoneally for pancreatic cancer. They have also administered the same along with chemotherapeutic drugs which showed no toxicity. With poorly localized malignant tumours such as glioblastoma and lymphatic metastasis intra-venous administration is preferred. However, the MNPs crossing the blood-brain-barrier is a challenging task. Ma.et.al[14] demonstrated an effective intraperitoneal administration in mouse of up to $5 \mathrm{mg} / \mathrm{Kg}$ weight above which oxidative damage to hepatic and renal tissues were observed. Magnetic hyperthermia was achieved successfully by direct injection of MNPs into urinary bladder via urinary catheter which was later removed by a catheter in order to prevent system toxicity. This study was performed in rat bladders by Oliveira, et.al[15] where they maintained a localized heat of about $42^{\circ} \mathrm{C}$ throughout. Pre-clinical trials on intra-arterial administration of chemotherapeutic drugs coupled with MNPs have been successfully tested on rabbits for liver cancer treatment wherein it was observed that there is greater tendency of the MNPs getting accumulated in the liver cancer cells via reticuloendothelial system[16]. Huang et.al [17]conducted a pre-clinical study on mice by injecting large quantity $(1,700 \mathrm{mg} \mathrm{Fe} / \mathrm{Kg})$ of unlabelled- MNPs intravenously and achieved an accumulation of $1.9 \mathrm{mg} \mathrm{Fe} / \mathrm{Kg}$ in tumour tissue with a tumour to non-tumour accumulation of $16: 1$ ratio due to enhanced permeability and retention (EPR) effect of the nano-particles in the tumour tissues because of their leaky vasculatures and poor lymphatic drainage. Huang et.al[17] also demonstrated that the administration of extremely large quantities of MNPs $(3,400 \mathrm{mg} \mathrm{Fe} / \mathrm{Kg})$ in mice have survived up to 12 months with no signs of toxicity.Delivery of MNPs into the blood stream requires it to be suspended in a fluid which is then called a magnetic fluid[18]. By using polymeric dispersants, the biocompatibility of the colloids is greatly improved[18]. Cellulose microcrystalline is an excellent biocompatible polymer used in food and pharmaceutical industries as emulsifiers and viscosity increasing agent. Human blood is a non-newtonian and thixotropic fluid where its viscosity decreases as the shear rate increases thus making it a viscoelastic fluid that eases out its flow in blood vessels that contracts and retracts exerting pressure on the fluid[19]. This is exactly the properties that are ideal for an injectable fluid into the blood stream. Viscoelastic fluids flow efficiently through syringes even at high shear rates exerted by the plunger (Fig. 1).

In this study we have explored the use of microcrystalline cellulose as the suspension fluid for magnetic nanoparticles to be injected into the tumoral site for hyperthermia treatment and the corresponding rheological behaviour of the fluid is discussed. The synthesis of highly coercive and highly stable maghemite nanoparticles and its relevant magnetic properties with hyperthermia measurements have also been discussed.

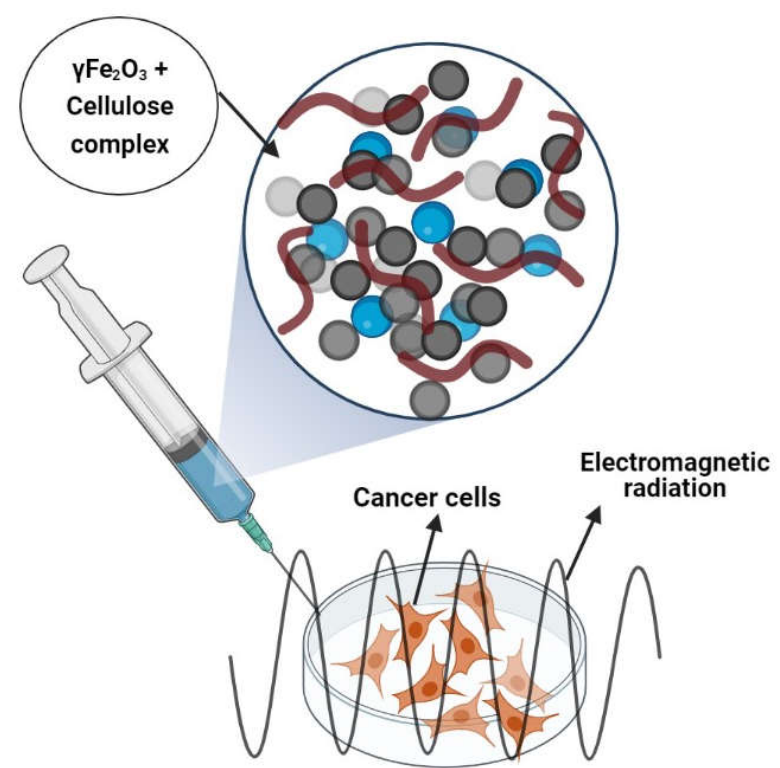

Figure 1: Gamma- $\mathrm{Fe}_{2} \mathrm{O}_{3}$ and cellulose microcrystalline polymer complex injected through a syringe to the targeted tumour cells for induction heating caused by electromagnetic radiation in hyperthermia treatment

\section{Experimental \\ Iron Oxide Nanoparticles Synthesis and Characterization}

$\mathrm{FeCl}_{2}$ and $\mathrm{FeCl}_{3}$ salts were taken in the ratio $4: 1$ and dissolved in $2 \mathrm{M} \mathrm{HCl} 100^{\circ} \mathrm{C}$. Ammonia was added drop wise until black coloured iron nano-particles $(\sim 100 \mathrm{~nm})$ precipitated and the solution was maintained throughout at $\mathrm{pH}$ 9. The black-coloured precipitated solution was immediately autoclaved at $200^{\circ} \mathrm{C}$ for 1 hour and the particles were washed to remove the unreacted chemical debris. The iron-oxide particles were then dried in oven at $100^{\circ} \mathrm{C}$ for 8 hours to get fine maghemite powder. All the chemicals were purchased from SRL chemicals, Mumbai. Further the synthesized nanoparticles were characterized by FIELD-EMISSION Scanning Electron Microscope (FESEM), X-Ray Diffraction Analysis (XRD), vibrating-sample magnetometer analysis (VSM), induction heating, DLS and zeta potential.

\section{Magnetic Fluid Preparation}

Microcrystalline cellulose of TLC grade purchased from SRL chemicals was dissolved in ortho-phosphoric acid and allowed to sonicate for 1 hour prior to letting it set in room temperature for 2 days to completely dissolve as a thick viscous fluid. The iron oxide nano-particles were sonicated in 1:1 ratio of glycerol and water mixture for half an hour and this solution was added to the cellulose solution keeping them constantly agitated in the sonicator bath in order to prevent agglomeration of the iron oxide nanoparticles.

\section{Physical Characterization}

Scanning electron microscope (SEM) analysis was performed using Carl Zeiss MA15 /EVO 18 Micro SEM with gold sputtering. X-ray Diffraction (XRD) analysis was carried out using PANalytical X-Pert Pro. Fourier transform 
infrared spectrometer was performed using Jasco International FTIR-6300. Vibrating sample magnetometer with dynamic magnetization was used to analyse the iron oxide powder samples with varying temperature.DLS and Zeta potential was performed with the help of Malvern Panalytical instrument.

\section{Magnetic Hyperthermia Analysis}

Hyperthermia experiment was performed with the help of EASYHEAT 8310, Ambrell, UK varying the coil diameter $7 \mathrm{~cm}$ [C76] and $9 \mathrm{~cm}$ [C94]), operating frequency $(178 \mathrm{KHz}$ and $242 \mathrm{KHz})$ and current $(200 \mathrm{~A}$ and $300 \mathrm{~A})$. The instrument was supplied with water circulation in order to maintain ambient temperature.

\section{Rheological Studies}

The behaviour of the carrier fluid plays a very important role as this determines how well the targeted drug or MNPs are delivered to the affected region through intra-venous route or by intra-tumoral route. Hence a rheological study for the fluid was also carried out using Physica MCR 301 rheometer.

\section{In-Vitro Cytotoxicity Assay}

In order to check the biocompatibility of the synthesized nanoparticles and the suspension a cytotoxicity test was performed on A549 (lung cancer) cell lines. The cell proliferation assay was done with filtered $5 \%$ human blood serum procured from blood bank and DMEM (high glucose) was used as the culture medium. $5 \% \mathrm{CO}_{2}$ was maintained in the incubator for carrying out the cell culture studies. $2 \%$ antibiotic was used for the medium. $50 \mu \mathrm{L}$ MTT was added to each well and incubated for 3 hours following which $150 \mu \mathrm{L}$ of DMSO was added to it and allowed to incubate for 15 minutes. Absorbance was taken at $590 \mathrm{~nm}$ to estimate the percentage of viable cells in comparison with the control samples by observing the purple color change that occurs due to the conversion of tetrazole into formazan by living cells. FDA and propidium iodide staining method was employed for fluorescent imaging of the viable and non-viable cells. Cytotoxicity was performed for both the powder and polymer suspension as well in separate 96-well culture plates.

\section{Results and Discussion}

Field Emission Scanning Electron Microscopic Studies Field emission scanning electron microscopic image (Figure 2) of the synthesized iron oxide nanoparticles, show that the particles are spherical in shape. Spherical nano-particles have better surface area to volume ratio and is preferred for in-vivo applications [20].

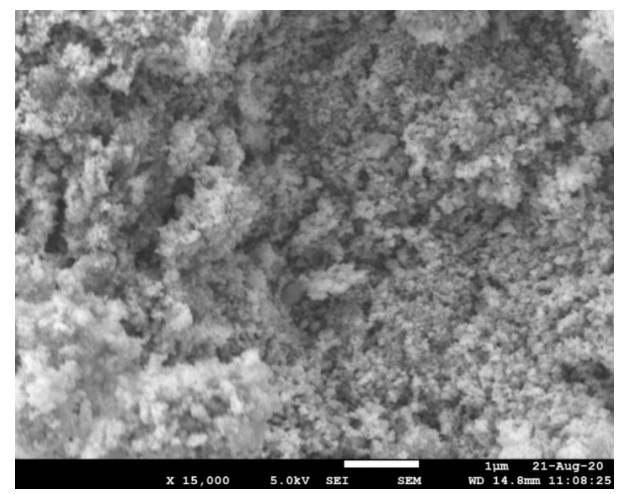

Figure 2: FE-SEM image of Iron oxide nano-particles

\section{Energy Dispersive X-Ray Analysis}

EDX was performed for the synthesized $\gamma-\mathrm{Fe}_{2} \mathrm{O}_{3}$ nanoparticles and elemental composition of the sample (Figure3) showed the presence of iron, carbon and oxygen and no other impurities were found[21].

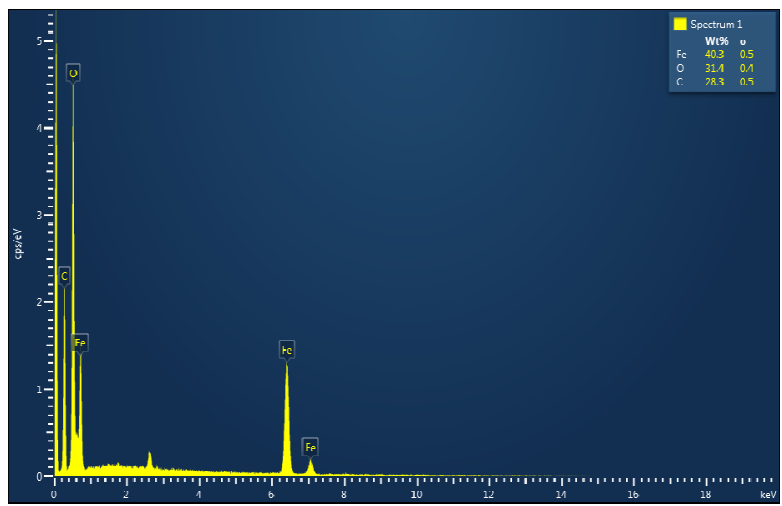

Figure 3: $\mathrm{EDX}$ data of the synthesized ${ }^{\gamma}-\mathrm{Fe}_{2} \mathrm{O}_{3}$ nanoparticles

\section{X-Ray Diffraction Analysis}

XRD pattern (Figure 4) confirms the maghemite $\left({ }^{\gamma}-\mathrm{Fe}_{2} \mathrm{O}_{3}\right)$ phase of the iron oxide nanoparticles. Maghemite nanoparticles are most preferred for biomedical hyperthermia treatment and are comparatively less toxic[22].

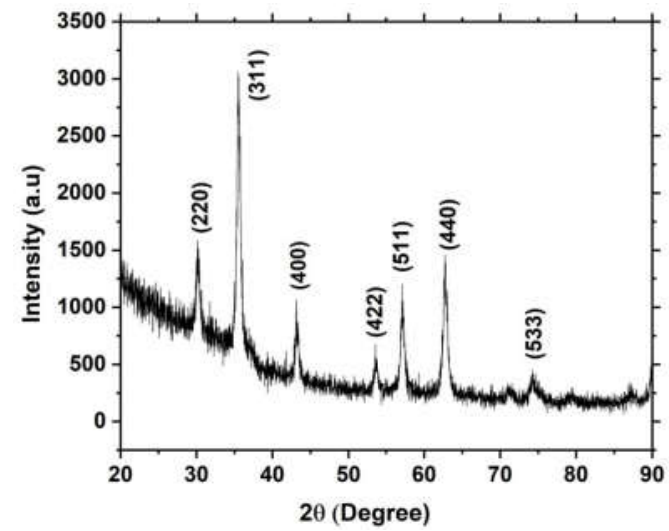

Figure 4: XRD pattern for the as synthesized ${ }_{-}-\mathrm{Fe}_{2} \mathrm{O}_{3}$ nanoparticles

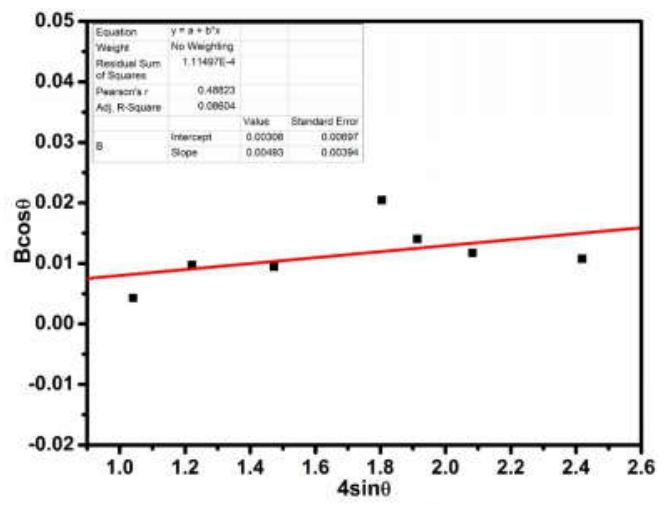

Figure 5: $\mathrm{W}$-H plot for ${ }^{\gamma}-\mathrm{Fe}_{2} \mathrm{O}_{3}$ nanoparticles

The JCPDS card number for the data is \#39-1346 $\left({ }^{\gamma}-\mathrm{Fe}_{2} \mathrm{O}_{3}\right)$. $\mathrm{Cao}$ et. al, (2016)[23] have synthesized pure ${ }^{\gamma}-\mathrm{Fe}_{2} \mathrm{O}_{3}$ particles by calcinating it at $200{ }^{\circ} \mathrm{C}$ for 2 hours and have also discussed the appearance of various phases of iron oxide at various calcination temperatures. However, by a combined heating method of iron oxide powder at $200{ }^{\circ} \mathrm{C}$ 
for 1 hour followed by calcination of the nanoparticles at $100^{\circ} \mathrm{C}$ for 8 hours $\gamma-\mathrm{Fe}_{2} \mathrm{O}_{3}$ was obtained as evidenced in Figure 4. The crystallite size of the iron oxide was calculated using Scherrer formula and it was found to be $21.3 \mathrm{~nm}[24]$. According to W-H plot(figure 5) the crystallite size was found to be $44 \mathrm{~nm}$ and the tensile strain was determined as $0.005 \mathrm{Nm}^{-2}$.

\section{DLS and Zeta Potential}

Dynamic light scattering technique was used to determine the particle size of the synthesized iron oxide nanoparticles (Figure 6). The average particle size of the synthesized iron oxide MNPs were found to be $106 \mathrm{~nm}$ which is ideal for invitro hyperthermia applications. Particle size greater than $200 \mathrm{~nm}$ will get easily removed by the spleen, hence in order to escape the RES (reticulo-endothelial system) the particle size should be less than or $\sim 100 \mathrm{~nm}$. Particle size ranging from 10-120 $\mathrm{nm}$ can enter the small capillaries that efficiently get distributed into the circulatory system, thereby reaching the affected tissues[25]. The zeta potential of the iron oxide nanoparticles was found to be $45.8 \mathrm{mV}$ which shows that the particles are stable in suspensions due to good electrostatic repulsion between them [26]. DLS and Zeta potential was taken in room temperature at $\mathrm{pH} 7$.

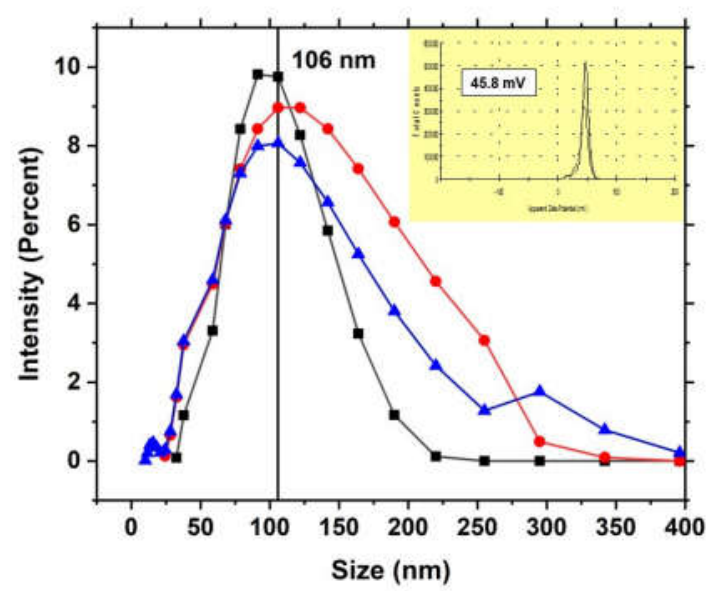

Figure 6: DLS and Zeta potential of the synthesized ${ }^{\gamma}-\mathrm{Fe}_{2} \mathrm{O}_{3}$ nanoparticles

Fourier-Transform Infrared Spectroscopy Studies

The FTIR spectrum (Figure 7) shows distinct peaks at 1604 $\mathrm{cm}^{-1}, 956 \mathrm{~cm}^{-1}, 2787 \mathrm{~cm}^{-1}$ corresponding to the cellulose suspension.

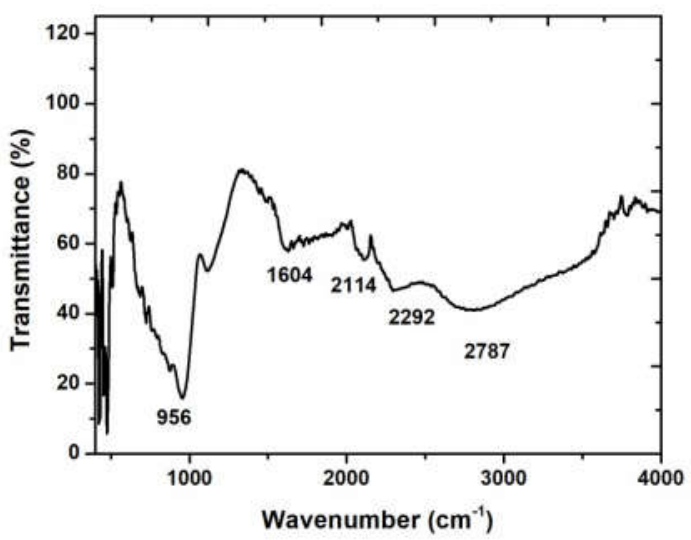

Figure 7: FTIR spectrum of cellulose microcrystalline solution
The peak at $1604 \mathrm{~cm}^{-1}$ and the broad peak at $2787 \mathrm{~cm}^{-1}$ has occurred due to the surface hydroxyl groups[27]. The peak at $956 \mathrm{~cm}^{-1}$ corresponds to the phosphate group present in orthophosphoric acid[28].

\section{Vibrating-Sample Magnetometer (VSM) Studies}

The powder was tested for its magnetic efficiency with the help of VSM technique with field strength varied from 15000 Oe to 15000 Oe. The resulting magnetism ranged between -1 emu to +1 emu. Dynamic magnetization was also performed for the powder samples by varying the temperature. At higher temperatures ( $400 \mathrm{~K}$ to $500 \mathrm{~K}$ ) the magnetic moment was found to be high. No saturation was found until 4000 Oe (Figure 8). The coercivity value $\left(\mathrm{H}_{\mathrm{c}}\right)$ was found to be 75.83 Oe whereas the retentivity $\left(\mathrm{Mr}_{\mathrm{r}}\right)$ was found to be $0.11 \mathrm{emu}$. The higher coercivity value indicates that the magnetic particles are stable in external magnetic field without getting demagnetized[29], the greater the coercivity, the higher is the SAR (specific absorption rate) for the nanoparticles[30]. Therefore, the synthesized MNPs are found to possess immense stability. Hematite particles exhibit lower magnetization and coercivity[31]. The coercivity of the particles depend on various factors such as particle size, structure, strain and twinning of the particles that gives rise to magneto-elastic anisotropy[32].

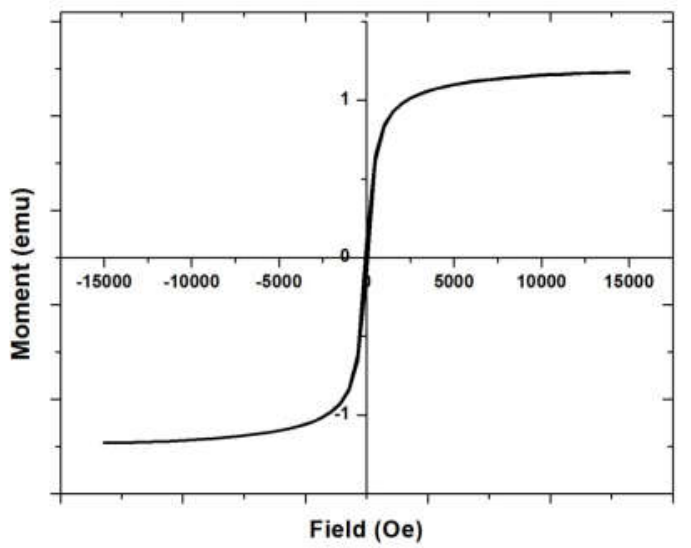

Figure 8: VSM magnetization of the as synthesized iron oxide nano particles

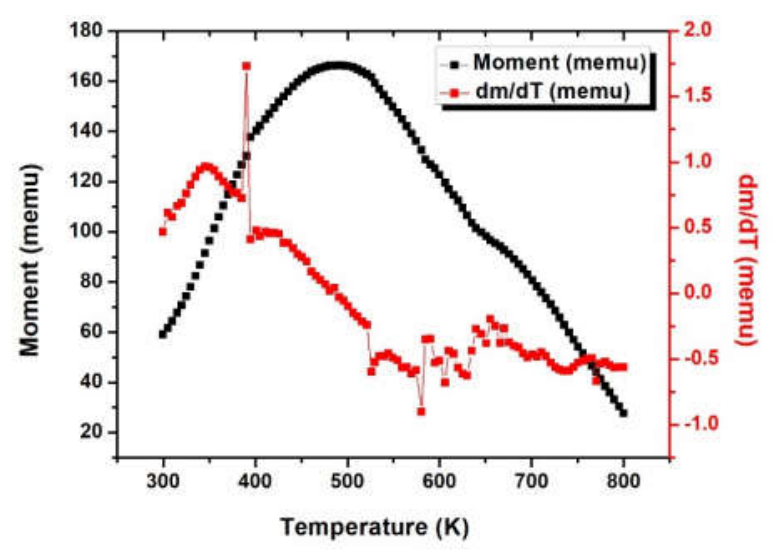

Figure 9: $d M / d T$ plot of as synthesized iron oxide nano-particles

Magnetic moment against temperature $(\mathrm{K})$ was plotted as shown in Figure 9. It could be observed that the lowest $\mathrm{dM} / \mathrm{dT}$ taken as an average Curie temperature of the MNPs $\left(\mathrm{T}_{\mathrm{c}}\right.$ ) is $582 \mathrm{~K}$ which is equivalent to $308.85^{\circ} \mathrm{C}$. This indicates the immense heating capacity of the MNPs which could be 

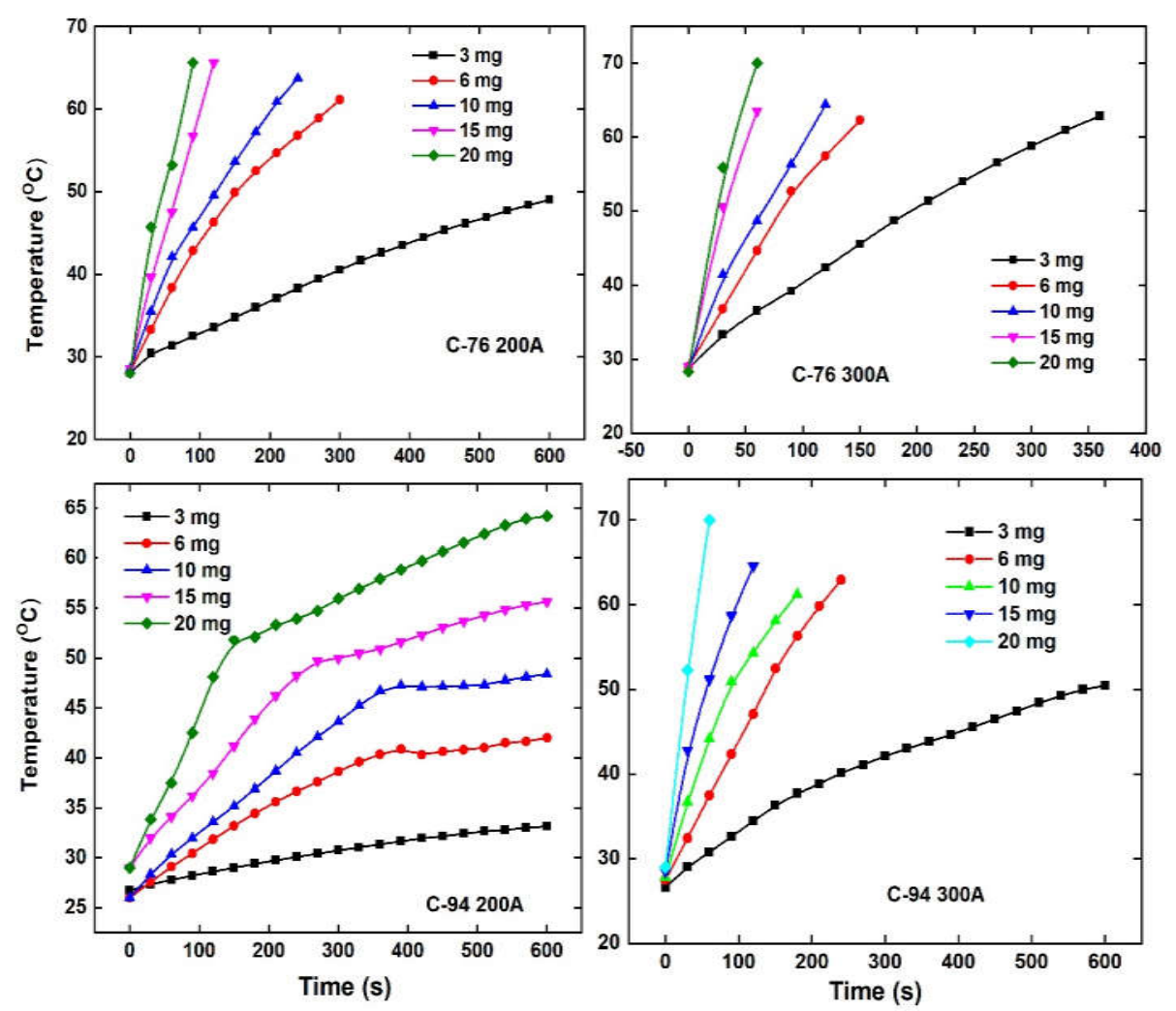

Figure 10: Induction heating profile of various concentration of maghemite powder using coils C76-200A, C76-300A, C94-200A and C94 300A

applicable for magnetic hyperthermia treatment. Yuanwei Chen et al. (2016)[33], synthesized and characterized nano-particle composite of lanthanum, strontium manganates. The $\mathrm{T}_{\mathrm{c}}$ values of the particles were ranging from $43.9^{\circ} \mathrm{C}-49.2^{\circ} \mathrm{C}$. Figure 9 indicates that the synthesized maghemite particles have a very high Curie temperature and signifies that the material loses its magnetic potential only beyond $300^{\circ} \mathrm{C}$. This result coincides with the high coercivity value obtained for the $100 \mathrm{~nm}$ size maghemite particles.

\section{Magnetic Hyperthermia Analysis}

Induction heating experiment was performed (Figure 10) by varying the coil diameter $(7 \mathrm{~cm}$ and $9 \mathrm{~cm})$, operating frequency (178 kHz and $242 \mathrm{kHz}$ ) and current (200A and $300 \mathrm{~A})$. The reason behind varying the copper coil diameter is that the resulting magnetic field generated is inversely proportional to the coil diameter. The heating efficiency is also directly proportional to the number of turns and the magnetic field generated. This is due to the fact that the heat generation depends on the square of magnetic field generation $\left(\mathrm{H}^{2}\right)$. The heat generated with $\mathrm{C} 76$ coil is higher than that of the heat generated with C94 coil which agrees with the fact that the increase in diameter of the $\mathrm{Cu}$ coil decreases the heat produced because magnetization also decreases. But however, the increase in concentration of the maghemite and increase in current $(300 \mathrm{~A})$ reduces the

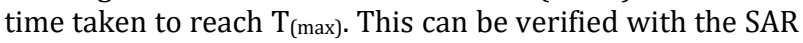
(specific absorption rate) calculated for all the powder samples at varying concentration. Induction heating reached $45.7^{\circ} \mathrm{C}$ in as low as 30 seconds of time with $\mathrm{C}-76$ coil at $200 \mathrm{~A}$ and $55.9^{\circ} \mathrm{C}$ with $\mathrm{C}-76$ at $300 \mathrm{~A}$ for $20 \mathrm{mg}$ of MNPs.
Furthermore, Induction heating was performed for the polymer-maghemite composite (Figure 11) with varying concentrations of polymer solution and the MNPs and SAR and ESAR values were analyzed. Constant current of 200A and C76 coil was used throughout the experiment as it was optimized from the experiment performed with gamma$\mathrm{Fe}_{2} \mathrm{O}_{3}$ powder (Figure 10).

The results for magnetic hyperthermia analysis indicate that SAR and ESAR values were the highest for $20 \mathrm{mg}$ concentration of iron oxide powder. Specific absorption rate is the efficiency of the material to generate heat by varying the concentration of the MNPs with alternating external magnetic field,whereas ESAR (Effective specific absorption rate) is the efficiency of heating observed under specific operating frequency, field strength and current applied. The highest SAR (145.25 W/g) (Figure 12) value was observed for $20 \mathrm{mg}$ concentration of iron oxide powder with C76 coil and the corresponding ESAR $(2.77 \mathrm{x}$ $10^{-3}$ ) (Table 2) value was found. P.Burnham et.al (2013) studied the SAR values of various sizes of ${ }^{\gamma}-\mathrm{Fe}_{2} \mathrm{O}_{3}$ particles with varying concentration of oleic acid and the minimum SAR for $16.2 \mathrm{~nm}$ particle and $0 \%$ oleic acid was found to be $0.126 \mathrm{~W} / \mathrm{g}$ and the maximum SAR value for $20 \%$ oleic acid with $7.3 \mathrm{~nm}$ of ${ }^{\gamma}-\mathrm{Fe}_{2} \mathrm{O}_{3}$ particles was found to be $11.08 \mathrm{~W} / \mathrm{g}$. The heating capability of the polymer and MNPs together showed an increased SAR (17 W/g) (Table 2) (Figure 13) and ESAR $\left(0.149 \times 10^{-3}\right)$ for the MNPs concentration of 20 $\mathrm{mg}$ and $5 \mathrm{ml}$ or the polymer solution. A maximum temperature of $43^{\circ} \mathrm{C}$ is reached in 60 seconds for the $20 \mathrm{mg}$ iron oxide dispersed in $2 \mathrm{ml}$ polymer solution. Mild hyperthermia therapy temperature usually ranges from 39 ${ }^{\circ} \mathrm{C}$ to $45^{\circ} \mathrm{C}[34]$. 


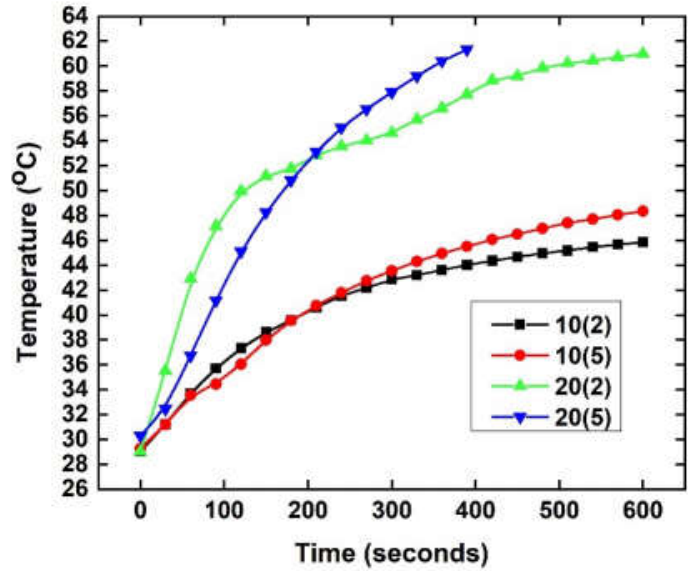

Figure 11: Induction heating profiles of varying concentration of iron oxide powder with cellulose concentration

$$
S A R=C \frac{\Delta T}{\Delta t} \frac{1}{m}
$$

Where $\mathrm{c}$ is the specific heat of water $(4.18 \mathrm{Jg}-1 \mathrm{~K}-1$ mol-1), $\mathrm{m}=$ mass of the maghemite and $\Delta \mathrm{T} / \Delta \mathrm{t}=$ slope of the temperature versus time plot. SAR is expressed in unit $\mathrm{W} / \mathrm{g}[24]$.

$$
E S A R=\frac{S A R}{H_{\text {applied }}^{2} f^{\prime}}
$$

Where $\mathrm{H}_{\text {applied }}$ is the applied magnetic field strength and $\mathrm{f}$ is the frequency of the applied field strength. Specific loss power (SLP) is directly proportional to SAR values, which means that the amount of heat produced is directly proportional of the amount of magnetic radiation absorbed by the particles with respect to its mass. Whereas ESAR values are more specific to the type of coil diameter, current applied and the magnetic field strength used [33]. It can be noted that the Effective Specific Absorption Rate (ESAR) observed for magnetite particles used for the application of hyperthermia reported by Jayadevan (2010) [35] has shown a highest ESAR value of $29.5 \times 10^{-9} \mathrm{Wg}^{-1} \mathrm{Oe}^{-}$ ${ }^{2} \mathrm{~Hz}^{-1}$ for the particles dispersed in water and $15.8 \times 10^{-9} \mathrm{Wg}^{-}$ $1 \mathrm{Oe}^{-2} \mathrm{~Hz}^{-1}$ for the particles dispersed in oil and PVA (polyvinyl alcohol).

Applied field strength is calculated with the following equation:

$$
H=\frac{1.257 n i}{D}(\mathrm{Oe})
$$

Where,

$H$ is the applied field strength

iis the applied current

$n$ is the number of turns of the coil used

$D$ is the diameter of the coil used

Table 1: The parameters used for hyperthermia experiment and the corresponding $\mathrm{Hf}$ value

\begin{tabular}{llllll}
\hline $\begin{array}{l}\text { Coil } \\
\text { diameter }\end{array}$ & $\begin{array}{l}\text { Operating } \\
\text { frequency (f) } \mathrm{kHz}\end{array}$ & $\begin{array}{l}\text { Current } \\
(\mathrm{A})\end{array}$ & \multicolumn{2}{l}{ Field strength (H) } & $\mathrm{Hf}(\mathrm{kA} \mathrm{m}-$ \\
\cline { 3 - 5 } 7 & \multirow{2}{*}{178} & 200 & 323.23 & 25.73 & $4.58 \times 10^{6}$ \\
\hline \multirow{2}{*}{2} & 300 & 215.48 & 17.15 & $3.05 \times 10^{6}$ \\
\hline \multirow{2}{*}{242} & 200 & 167.60 & 13.33 & $3.22 \times 10^{6}$ \\
\hline
\end{tabular}

Table 2: SAR and ESAR values for various concentrations of iron

\begin{tabular}{|c|c|c|c|c|c|c|c|c|}
\hline $\begin{array}{l}\text { Maghemite } \\
\text { conc }\end{array}$ & $\begin{array}{l}\text { SAR } \\
\text { (W/g) }\end{array}$ & $\begin{array}{l}\text { ESAR } \\
\text { (x 10- } \\
3 \text { ) }\end{array}$ & $\begin{array}{l}\text { SAR } \\
(W / g)\end{array}$ & $\begin{array}{l}\text { ESAR( } \\
\left.\times 10^{-3}\right)\end{array}$ & $\begin{array}{l}\text { SAR } \\
(W / g)\end{array}$ & $\begin{array}{l}\text { ESAR } \\
\text { (x 10 } \\
3 \text { ) }\end{array}$ & $\begin{array}{l}\text { SAR } \\
(W / g)\end{array}$ & $\begin{array}{l}\text { ESAR } \\
\left(x \quad 10^{-3}\right)\end{array}$ \\
\hline & \multicolumn{2}{|c|}{ C76-200A } & \multicolumn{2}{|c|}{ C76-300A } & \multicolumn{2}{|c|}{ C94-200A } & \multicolumn{2}{|c|}{ C94-300A } \\
\hline $3 \mathrm{mg}$ & 47.93 & 0.406 & 130.8 & 2.4 & 14.63 & 0.34 & 52.52 & 2.74 \\
\hline $6 \mathrm{mg}$ & 74.4 & 0.631 & 156.88 & 2.9 & 18.04 & 0.419 & 105.26 & 5.50 \\
\hline $10 \mathrm{mg}$ & 59.18 & 0.502 & 120.46 & 2.3 & 15.75 & 0.366 & 76.28 & 3.97 \\
\hline $15 \mathrm{mg}$ & 84.6 & 0.717 & 160.23 & 3.06 & 11.75 & 0.273 & 81.78 & 4.27 \\
\hline $20 \mathrm{mg}$ & 83.8 & 0.711 & 145.25 & 2.77 & 10.40 & 0.241 & 142.8 & 7.46 \\
\hline
\end{tabular}
oxide powder under varying coil diameter, field strength and current

Table 3: SAR and ESAR values for varying concentrations of polymer+MNPs complex

\begin{tabular}{ccc}
\hline $\begin{array}{c}\text { Polymer+maghemite } \\
\text { concentration }\end{array}$ & SAR $(\mathrm{W} / \mathrm{g})$ & ESAR $\left(\times 10^{-3}\right)$ \\
\hline $10(2)$ & 10.28 & 0.090 \\
$10(5)$ & 12.70 & 0.111 \\
$20(2)$ & 8.38 & 0.073 \\
$20(5)$ & 17 & 0.149 \\
\hline
\end{tabular}

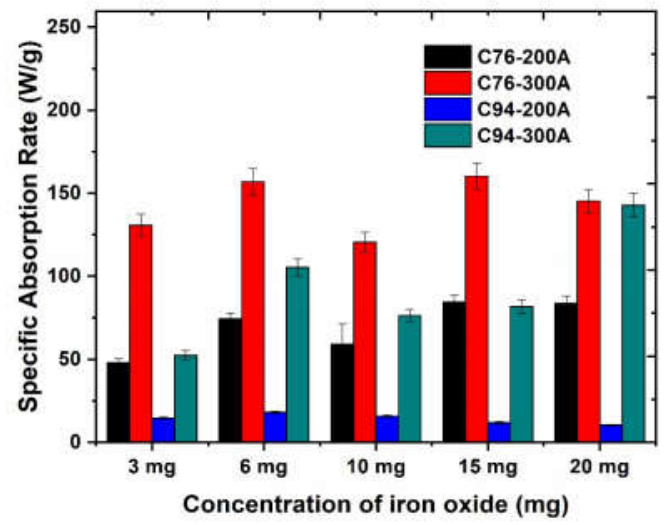

Figure 12: SAR values of maghemite particles at various concentrations

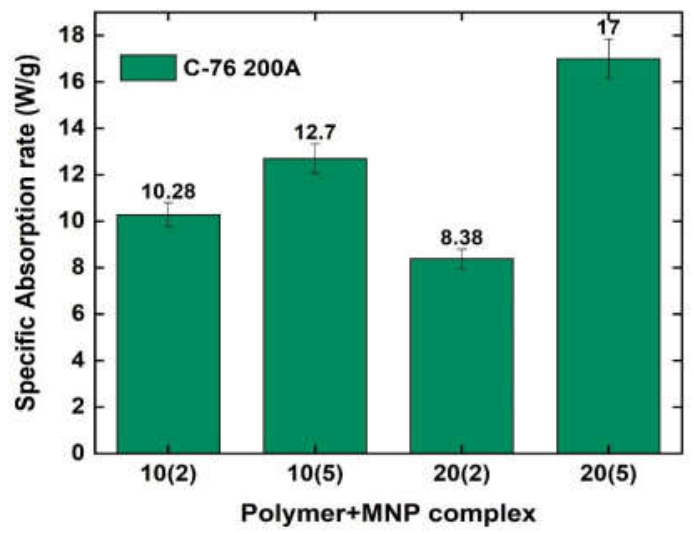

Figure 13: SAR values of MNPs dispersed in polymeric medium

\section{Rheological Study}

Human whole blood carrying white-blood cells and red blood cells acts as a viscoelastic, pseudo-plastic (Figure 14) and thixotropic fluid which becomes less viscous during higher shear stress and gains back its original viscosity at low shear stress[36]. This kind of fluid with thixotropic shear-thinning behaviour is well preferred for pharmaceutical formulations to carry metal ions or drugs to the targeted sites[37]. Therefore, in Figure 14 it is 
observed that the shear stress also increases as the shear rate increases and goes back to 0 as the shear rate decreases. This shows the stability of the fluid. The influence of thixotropic behaviour in magnetic ferrofluid was reported by Yang et.al, (2010) [38].

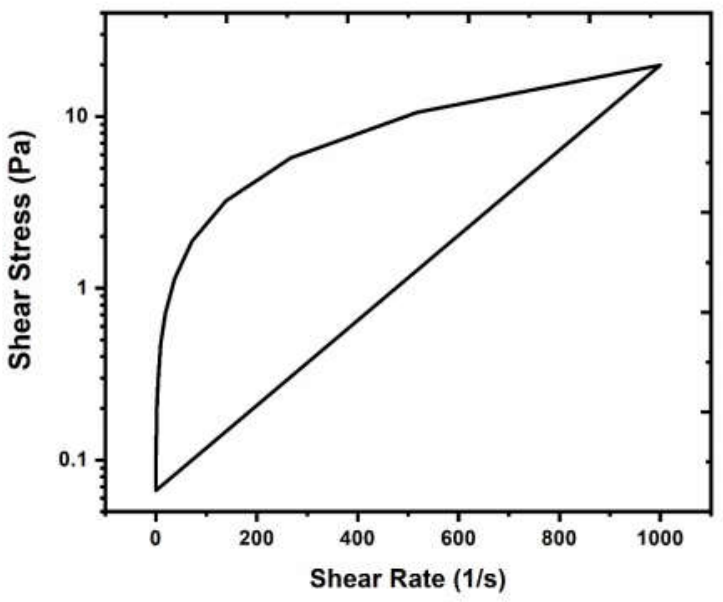

Figure 14: Shear rate vs Shear stress plot for the cellulose/orthophosphoric suspension

The cellulose fluid is viscous at room temperature without stress whereas in Figure 15 one can observe that the viscosity readily decreases as the stress increases. This is the typical behaviour of blood. The fluid carrying the targeted particles should reach the affected tumour site irrespective of the rough passages it may have to travel through. Especially in cancer affected regions the blood vasculatures will be extremely knotted with various valve thickenings with a lot of contractions; hence the fluid should have shear-thinning properties in order to reach the targeted tissue/cells successfully with the MNPs. The viscosity (Figure 15) steadily decreases with increase in shear stress and then gets restored back to its original viscosity when the stress is lowered. This exactly coincides with the thixotropic and pseudo-plastic behavior of human blood [36].

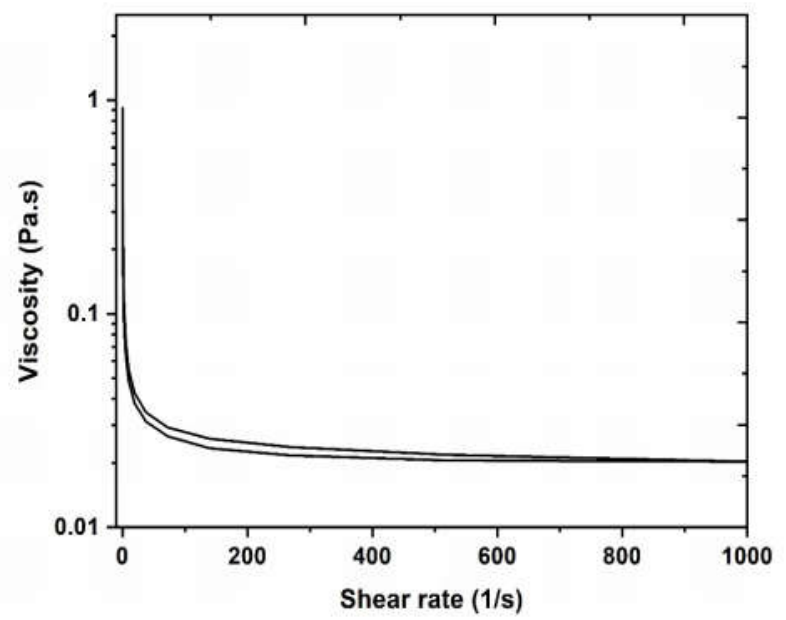

Figure 15: Shear rate vs viscosity plot of the cellulose/orthophosphoric fluid showing a typical thixotropic, shear-thinning behaviour

\section{Cell Culture Studies}

The cytotoxicity of the iron oxide nano-particles was tested with lung cancer cells for Day 2 and Day 4. It is observed that there is decrease in cell proliferation on day 4 , of which $50 \mathrm{mg}$ of iron oxide showed significant decrease in cell proliferation on day 4 when compared to the control samples (Figure 16). The cell proliferation assay was done with 5\% human blood serum procured from blood bank and DMEM (high glucose) was used as the culture medium. $5 \% \mathrm{CO}_{2}$ was maintained in the incubator for carrying out the cell culture studies. $2 \%$ antibiotic was used for the medium. MTT assay was used to estimate the number of viable and non-viable cells. FDA staining method was employed for fluorescent imaging (Figure 18) of the viable and non-viable cells. Cytotoxicity was performed for both the powder and polymer suspension as well in separate 96well culture plates.

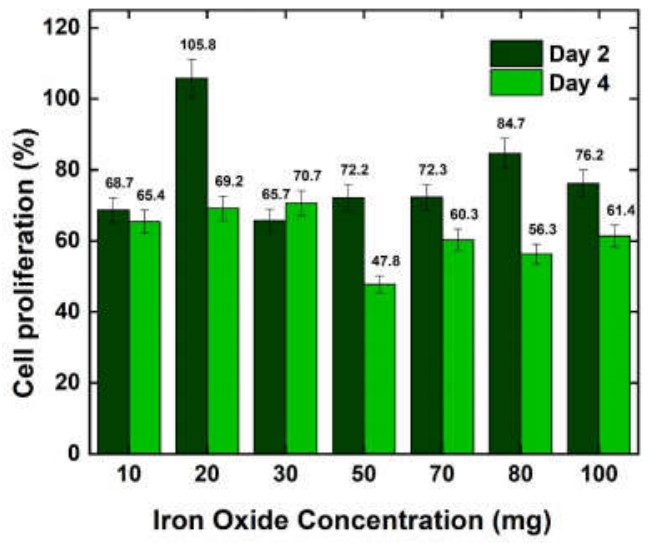

Figure 16: Lung cancer cell proliferation rate of various concentrations of iron oxide nano-particles

The cell culture results showed that the iron oxide nano particles are toxic to the lung cancer cells beyond $20 \mathrm{mg}$ (Fig. 16) the polymer suspension (Fig. 17) showed good proliferation of the cancer cells which also indicates that the cellulose microcrystalline suspension is non-toxic to the non-cancerous cells. The rate of proliferation decreases with increase in incubation time.

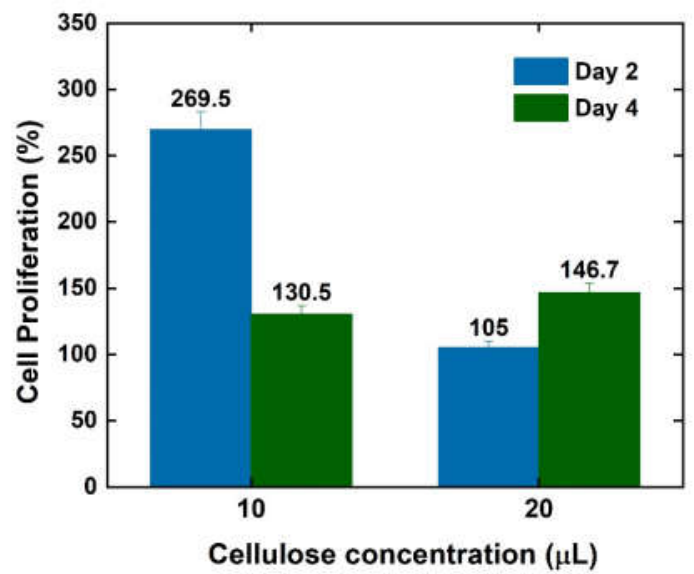

Figure 17: Cell proliferation \% of lung cancer cells with various concentrations of cellulose suspension fluid

The red coloured cells shown in Figure 18 are the dead cancer cells shown under fluorescent microscope taken on Day 4. The lung cancer cells showed high sensitivity to 50 mg of iron oxide nano-particles. The density of the dead 
cells was higher with $20 \mathrm{ml}$ of polymeric suspension (Figure 18). Human blood serum was used in replacement of FBS (foetal bovine serum) in order to practice humane way of cell culturing. The percentage of human blood serum to be used was optimized with FBS by performing a thorough comparative study with equal concentrations of both in two different 96-well plates. And it was found that the results we obtained with $8 \%$ foetal bovine serum matched with that of $5 \%$ human blood serum and hence $5 \%$ human blood serum was optimized as the final concentration. In fact, the results were much enhanced with the usage of human blood serum when compared to the use of foetal bovine serum. The human blood serum was filtered with $0.45 \mu \mathrm{m}$ syringe filter before use. (a)
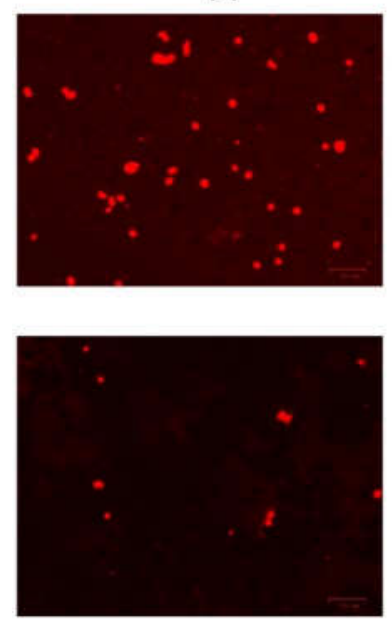

(c) (b)
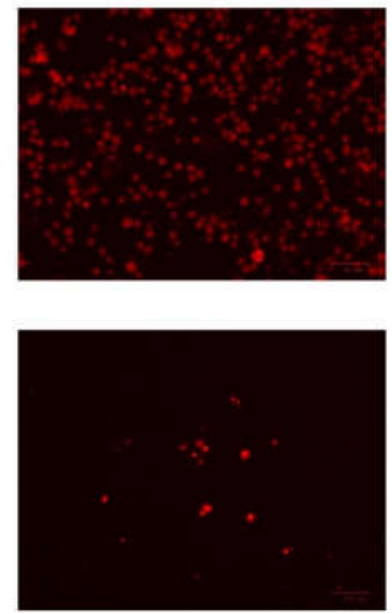

(d)
Figure 18: FDA staining and fluorescent images of lung cancer cells, (a) non-viable cells found on day 4 with $10 \mathrm{mg}$ of iron oxide nano-particles, (b) dead cancer cells on day 4 with $50 \mathrm{mg}$ of iron oxide nano-particles, (c) dead cancer cells on day 4 with $10 \mathrm{ml}$ of cellulose/ortho-phosphoric acid polymeric suspension, (d) dead cancer cells on day 4 with $20 \mathrm{ml}$ of cellulose/ortho-phosphoric polymeric suspension

\section{Conclusions}

The hydrothermal synthesis of maghemite nano-particles showed good magnetic properties which are evidenced from VSM and temperature-dependent VSM plots. The curie temperature $\left(\mathrm{T}_{\mathrm{c}}\right)$ of the synthesized magnetic iron oxide nano-particles were found to be between the range $43 .{ }^{\circ} \mathrm{C}-49.2^{\circ} \mathrm{C}$. Higher coercivity value of 75.83 Oe for the MNPs which indicate that the particles are extremely stable. The specific absorption rate (SAR) (145.25 W/g) with respect to the mass of the particles was highest for 20 mg maghemite particles whereas highest SAR $(17 \mathrm{~W} / \mathrm{g})$ was observed for $20 \mathrm{mg}$ of maghemite particles dispersed in $5 \mathrm{ml}$ of the polymeric (cellulose in ortho-phosphoric acid) medium. For $20 \mathrm{mg}$ of the iron oxide nano particles induction heating up to $55.9^{\circ} \mathrm{C}$ was observed within 30 seconds. The hyperthermia heating experiment performed for all the powder and suspended samples showed good heating efficiency when $7 \mathrm{~cm} \mathrm{Cu}$ coil was used under 300A of current. The highest temperature reached for the iron oxide nano-particles with the polymeric solution was $43^{\circ} \mathrm{C}$ within 60 seconds which is an ideal temperature for mild heating recommended for hyperthermia treatment. The rheological properties of the cellulose polymer suspension also showed that the fluid is viscoelastic with shearthinning properties that is similar to the thixotropic human blood. This type of rheological behaviour of the polymeric suspension is most preferred for pharmaceutical formulations of various types of drug carriers. In-vitro cell culture with lung cancer cells have shown that increase in concentration of MNPs and polymer solution leads to cell death.

\section{Acknowledgement:}

We sincerely thank DST-WOS(A) for providing the funds to carry out the entire research work. We also thank Dr. C. Gopalakrishnan and Mr. Jaison Darson from Nanotechnology Research Centre, SRM University for helping us carry out VSM analysis. We also thank Dr. Raghunandhakumar Subramanian and Dr.K. Pavani of Centre for Biotechnology, Anna University, Chennai for supplying us with cell lines to carry out the cytotoxicity test. We also thanks Dr. K. Saravanan of Department of Physics, Anna University for helping me with W-H plot.

"This work has been carried out in loving memory of Maana, whom we lost to Cancer"

\section{References}

1. P.J. Hoopes, R.R. Strawbridge, U.J. Gibson, Q. Zeng, Z.E. Pierce, M. Savellano, J.A. Tate, J.A. Ogden, I. Baker, R. Ivkov, A.R Foreman, Intratumoral iron oxide nanoparticle hyperthermia and radiation cancer treatment, Therm. Treat. Tissue Energy Deliv. Assess, IV, 2007, 6440, 64400K, International society for optics and photonics.

2. C. Yadel, A. Michel, S. Casale, J. Fresnais, Hyperthermia efficiency of magnetic nanoparticles in dense aggregates of cerium oxide/iron oxide nanoparticles, Appl. Sci. 2018, 8(8), 1241.

3. N.A. Usov, O.N. Serebryakova, V.P. Tarasov, Interaction Effects in Assembly of Magnetic Nanoparticles, Nanoscale Res. Lett, 2017, 12(1), 1-8.

4. J.R. Lepock, Measurement of protein stability and protein denaturation in cells using differential scanning calorimetry, Methods, 2005, 35(2), 117-125.

5. A. Jordan, P. Wust, H. Fähling, W. John, A. Hinz, R. Felix, Inductive heating of ferrimagnetic particles and magnetic fluids: Physical evaluation of their potential for hyperthermia, Int. J. Hyperth, 2009, 9(1), 51-68.

6. B. Rau, P. Wust, W. Tilly, J. Gellermann, C. Harder, H. Riess, V. Budach, R. Felix, P.M. Schlag, Preoperative radiochemotherapy in locally advanced or recurrent rectal cancer: Regional radiofrequency hyperthermia correlates with clinical parameters, Int. J. Radiat. Oncol. Biol. Phys, 2000,48(2), 381-391.

7. C.S.S.R. Kumar, F. Mohammad, Magnetic nanomaterials for hyperthermia-based therapy and controlled drug delivery, Adv. Drug Deliv. Rev, 2011, 63(9), 789-808.

8. C.W. Song, H.J. Park, C.K. Lee, R. Griffin, Implications of increased tumor blood flow and oxygenation caused by mild temperature hyperthermia in tumor treatment, in: Int. J. Hyperth, 2005, 21(8), 761-767.

9. D. Chang, M. Lim, J.A.C.M. Goos, R. Qiao, Y.Y. Ng, F.M. Mansfeld, M. Jackson, T.P. Davis, M. Kavallaris, Biologically targeted magnetic hyperthermia: Potential and limitations, Front. Pharmacol, 2018, 9, 831.

10.A.J. Peer, M.J. Grimm, E.R. Zynda, E.A. Repasky, Diverse immune mechanisms may contribute to the survival benefit seen in cancer patients receiving hyperthermia, Immunol. Res, 2010, 46(1), 137-154.

11.A. Kirschning, L. Kupracz, J. Hartwig, New synthetic opportunities in miniaturized flow reactors with inductive heating, Chem. Lett, 2012, 41(6), 562-570.

12.M. Johannsen, U. Gneveckow, L. Eckelt, A. Feussner, N. Waldöfner, R. Scholz, S. Deger, P. Wust, S.A. Loening, A. 
Jordan, Clinical hyperthermia of prostate cancer using magnetic nanoparticles: Presentation of a new interstitial technique, Int. J. Hyperth, 2005, 21(7), 637-647.

13.N. Gao, E.N. Bozeman, W. Qian, L. Wang, H. Chen, M. Lipowska, C.A. Staley, Y. Andrew Wang, H. Mao, L. Yang, Tumor penetrating theranostic nanoparticles for enhancement of targeted and image-guided drug delivery into peritoneal tumors following intraperitoneal delivery, Theranostics, 2017, 7(6), 1689.

14.P. Ma, Q. Luo, J. Chen, Y. Gan, J. Du, S. Ding, Z. Xi, X. Yang, Intraperitoneal injection of magnetic Fe304-nanoparticle induces hepatic and renal tissue injury via oxidative stress in mice, Int. J. Nanomedicine, 2012, 7, 4809.

15.T.R. Oliveira, P.R. Stauffer, C.T. Lee, C.D. Landon, W. Etienne, K.A. Ashcraft, K.L. McNerny, A. Mashal, J. Nouls, P.F. MacCarini, W.F. Beyer, B. Inman, M.W. Dewhirst, Magnetic fluid hyperthermia for bladder cancer: A preclinical dosimetry study, Int. J. Hyperth, 2013, 29(8), 835-844.

16.I.J. Lee, C.H. Ahn, E.J. Cha, I.J. Chung, J.W. Chung, Y. Il Kim, Improved drug targeting to liver tumors after intra-arterial delivery using superparamagnetic iron oxide and iodized oil: Preclinical study in a rabbit model, Invest. Radiol, 2013, 48(12), 826-833.

17.H.S. Huang, J.F. Hainfeld, Intravenous magnetic nanoparticle cancer hyperthermia, Int. J. Nanomedicine, 2013, 8, 2521.

18.A. Józefczak, T. Hornowski, Z. Rozynek, A. Skumiel, J.O. Fossum, Rheological study of dextran-modified magnetite nanoparticle water suspension, Int. J. Thermophys, 2013, 34(4), 609-619.

19.G.B. Thurston, Rheological parameters for the viscosity viscoelasticity and thixotropy of blood, Biorheology, 1979, 16(3), 149-162.

20.V. Shah, C. Malardier-Jugroot, M. Jugroot, Mediating gold nanoparticle growth in nanoreactors: Role of template-metal interactions and external energy, Mater. Chem. Phys, 2017, 196, 92-102.

21.P. Katikaneani, A.K. Vaddepally, N. Reddy Tippana, R. Banavath, S. Kommu, Phase Transformation of Iron Oxide Nanoparticles from Hematite to Maghemite in Presence of Polyethylene Glycol: Application as Corrosion Resistant Nanoparticle Paints, J. Nanosci, 2016.

22.E.A. Kuchma, P. V. Zolotukhin, A.A. Belanova, M.A. Soldatov, T.A. Lastovina, S.P. Kubrin, A. V. Nikolsky, L.I. Mirmikova, A. V. Soldatov, Low toxic maghemite nanoparticles for theranostic applications, Int. J. Nanomedicine, 2017, 12, 6365.

23.D. Cao, H. Li, L. Pan, J. Li, X. Wang, P. Jing, X. Cheng, W. Wang, J. Wang, Q. Liu, High saturation magnetization of $\gamma 3-\mathrm{Fe} 203$ nano-particles by a facile one-step synthesis approach, Sci. Rep, 2016, 6(1), 1-9.

24.G.S. Ningombam, R.S. Ningthoujam, S.N. Kalkura, N.R. Singh, Induction Heating Efficiency of Water-Dispersible Mn0.5Fe2.504@YV04:Eu3+_Magnetic-Luminescent Nanocomposites in an Acceptable ac Magnetic Field: Hemocompatibility and Cytotoxicity Studies, J. Phys. Chem. B, 2018, 122(27), 6862-6871.

25.M. Iacob, C. Racles, M. Dascalu, C. Tugui, V. Lozan, M. Cazacu, Review Article Nanomaterials Developed by Processing Iron Coordination Compounds for Biomedical Application, 2019.

26.E. Joseph, G. Singhvi, Multifunctional nanocrystals for cancer therapy: A potential nanocarrier, in: Nanomater. Drug Deliv. Ther, 2019, 1, 91-116.

27.N. Jia, S.M. Li, M.G. Ma, J.F. Zhu, R.C. Sun, Synthesis and characterization of cellulose-silica composite fiber in ethanol/water mixed solvents, BioResources, 2011, 6(2), 1186-1195.

28.C. Combes, C. Rey, Amorphous calcium phosphates: Synthesis, properties and uses in biomaterials, Acta Biomater, 2010, 6(9), 3362-3378.

29.E.C. Abenojar, S. Wickramasinghe, J. Bas-Concepcion, A.C.S. Samia, Structural effects on the magnetic hyperthermia properties of iron oxide nanoparticles, Prog. Nat. Sci. Mater. Int, 2016, 26(5), 440-448.

30.A.J. Giustini, A.A. Petryk, S.M. Cassim, J.A. Tate, I. Baker, P.J.
Hoopes, Magnetic Nanoparticle Hyperthermia in cancer treatment, Nano Life, 2010, 1(01n02), 17-32.

31.Özdemir Ö, Dunlop DJ, Berquo TS. Morin transition in hematite: Size dependence and thermal hysteresis. Geochemistry, Geophysics, Geosystems, 2008, 9(10).

32.H. Porath, C.B. Raleigh, An origin of the triaxial basal-plane anisotropy in hematite crystals, J. Appl. Phys, 1967, 38(5), 2401-2402.

33.Y. Chen, Y. Wang, X. Liu, M. Lu, J. Cao, T. Wang, LSMO Nanoparticles Coated by Hyaluronic Acid for Magnetic Hyperthermia, Nanoscale Res. Lett, 2016, 11(1), 1-6.

34.S. V. Spirou, M. Basini, A. Lascialfari, C. Sangregorio, C. Innocenti, Magnetic hyperthermia and radiation therapy: Radiobiological principles and current practice, Nanomaterials, 2018, 8 (6) 401.

35.B. Jeyadevan, Present status and prospects of magnetite nanoparticles-based hyperthermia, J. Ceram. Soc. Japan, 2010, 118 (1378) 391-401.

36.T. Sochi, Non-Newtonian Rheology in Blood Circulation, 2013,1306, 2067.

37.C.H. Lee, V. Moturi, Y. Lee, Thixotropic property in pharmaceutical formulations, J. Control. Release, 2009, 136 (2), 88-98.

38.C. Yang, Z. Liu, M. Yu, X. Bian, The influence of thixotropy on the magnetorheological property of oil-based ferrofluid, J. Mol. Liq, 2020, 320, 114425. 